\title{
Black Esophagus: A Rare Cause of Gastrointestinal Hemorrhage in the Emergency Department
}

Jason Arthur MD, MPH; Dave Caro, MD; Davis Lester, MD; Zachary Hester, MD; Valery Muenyi, MD

\section{In this case presentation of a 65-year-old man who presented to the ED for evaluation of a 1-week history of intermittent coffee-ground emesis and syncope, the authors review the literature about a rare, but potentially fatal diagnosis.}

\section{Case}

A 65-year-old man presented to the ED for evaluation of a 1-week history of intermittent, exertional syncope and coffee ground emesis. His medical history was significant for hypertension, peripheral vascular disease, hyperlipidemia, and peptic ulcer disease. Although his social history was positive for alcohol use and abuse, the patient stated that he had not consumed any alcoholic beverages since the onset of nausea and vomiting.

A review of the patient's systems was positive for lightheadedness upon standing and for palpitations. He had no prior history of melena, hematochezia, or syncope, but did report a previous history of upper gastrointestinal (GI) bleeding due to peptic ulcer disease and alcohol abuse.

The patient's vital signs at presentation were: blood pressure (BP), 114/74 mm Hg; heart rate, 112 beats/min; respiratory rate, 15 breaths/min; and temperature, $97.7^{\circ} \mathrm{F}$. Oxygen saturation was $97 \%$ on room air. On examination, the patient was conversant and oriented. He had dried blood around his mouth and chin from vomiting and appeared ill but nontoxic. His mucous membranes were pale. The cardiopulmonary examination was remarkable for tachycardia; however, the patient's extremities were warm and his capillary refill time was normal. The rectal examination was notable for melenic stool, which was guaiac positive. During the patient's course in the ED, he passed a large, melenic stool. The remainder of the physical examination was normal.

The chest X-ray was normal, but the electrocardiogram demonstrated sinus tachycardia. Laboratory studies were remarkable for the following:

Dr Arthur is an assistant professor and emergency ultrasound fellow, department of emergency medicine, University of Arkansas for Medical Sciences, Little Rock. Dr Caro is an associate professor and emergency medicine residency program director, department of emergency medicine, University of Florida College of Medicine, Jacksonville. Dr Lester is an emergency medicine resident physician, department of emergency medicine, University of Florida College of Medicine, Jacksonville. Dr Hester is an emergency medicine resident physician, department of emergency medicine, University of Florida College of Medicine, Jacksonville. Dr Muenyi is a gastroenterology fellow, department of medicine, division of gastroenterology, University of Florida College of Medicine, Jacksonville.

Authors' Disclosure Statement: The authors report no actual or potential conflict of interest in relation to this article.

DOI: 10.12788/emed.2018.0101 
hemoglobin (Hgb), $12.7 \mathrm{~g} / \mathrm{dL}$;

platelet count, $97 \times 109 / \mathrm{L}$;

sodium, $122 \mathrm{mmol} / \mathrm{L}$;

chloride, $73 \mathrm{mmol} / \mathrm{L}$;

potassium, $2.9 \mathrm{mmol} / \mathrm{L}$;

blood urea nitrogen, $121 \mathrm{mg} / \mathrm{dL}$;

creatinine, $1.89 \mathrm{mg} / \mathrm{dL}$;

glucose, $297 \mathrm{mg} / \mathrm{dL}$;

calcium, $7.9 \mathrm{mg} / \mathrm{dL}$;

anion gap, $27 \mathrm{mmol} / \mathrm{L}$;

total bilirubin, $1.6 \mathrm{mg} / \mathrm{dL}$ (mildly elevated);

direct bilirubin, $0.5 \mathrm{mg} / \mathrm{dL}$;

aspartate aminotransferase, $41 \mathrm{IU} / \mathrm{L}$; and

lactic acid, $5.5 \mathrm{mmol} / \mathrm{L}$ (elevated).

The patient's international normalized ratio and activated partial thromboplastin time were normal. There were no recent prior laboratory studies available for comparison with current findings.

Two large bore intravenous (IV) lines were placed, and the patient was resuscitated with a bolus of $20 \mathrm{~mL} / \mathrm{kg}$ of isotonic fluids. He was given $1 \mathrm{~g}$ of ceftriaxone and $80 \mathrm{mg}$ of pantoprazole IV and was started on an infusion of octreotide. Meanwhile, the patient was consented for blood products and $2 \mathrm{U}$ of packed red blood cells were crossmatched and held in reserve. He received potassium repletion of $60 \mathrm{mEq}$ IV potassium chloride.

The emergency physician (EP) consulted with gastroenterology services. Due to concern for variceal bleeding and to control hemorrhaging, the gastroenterologist recommended emergent upper endoscopy. The upper endoscopy revealed circumferential necrosis of the distal third of the esophagus, which stopped abruptly at the gastroesophageal junction (Figures 1-3). Since no varices were demonstrated on endoscopy, octreotide was discontinued. The gastroenterologist recommended the patient receive nothing orally for 24 hours and that he continue to receive IV proton pump inhibitors (PPIs) and empiric antibiotics. The patient was admitted to the medical intensive care unit (ICU) for further care.

Following admission to the ICU, the patient did not have any additional episodes of hematemesis or melenic or bloody stools. However, his Hgb levels down-trended to 8.6 $\mathrm{g} / \mathrm{dL}$ and his BP decreased to $84 / 63 \mathrm{~mm} \mathrm{Hg}$. He was transfused a single unit of packed red blood cells, after which BP normalized and Hgb stabilized at 9.5 g/dL. The patient's diet was advanced on hospital day 1 to clear liquids and then solid foods, and he was discharged home on hospital day 2 with prescriptions for pantoprazole $40 \mathrm{mg}$ twice daily and ranitidine $300 \mathrm{mg}$ nightly and with close primary care and gastroenterology follow-up.

\section{Discussion}

Black esophagus, also referred to as acute esophageal necrosis (AEN) or necrotizing esophagitis, is an uncommon, but life-threatening cause of GI bleeding. ${ }^{1}$ First described by Brennan ${ }^{2}$ during a patient autopsy in 1967, black esophagus remained a postmortem finding until its first description on endoscopy by Goldenberg et $\mathrm{al}^{3}$ in 1990 . With the increased use of endoscopy, black esophagus has been more commonly described in case reports and case series but remains an extremely rare diagnosis, with an incidence of $0.008 \%$ to $0.2 \%{ }^{4-7} \mathrm{~A}$ single study by Yasuda et $\mathrm{al}^{8}$ demonstrated a surprising incidence of AEN in 6\% of patients undergoing upper endoscopy for upper GI hemorrhage. 


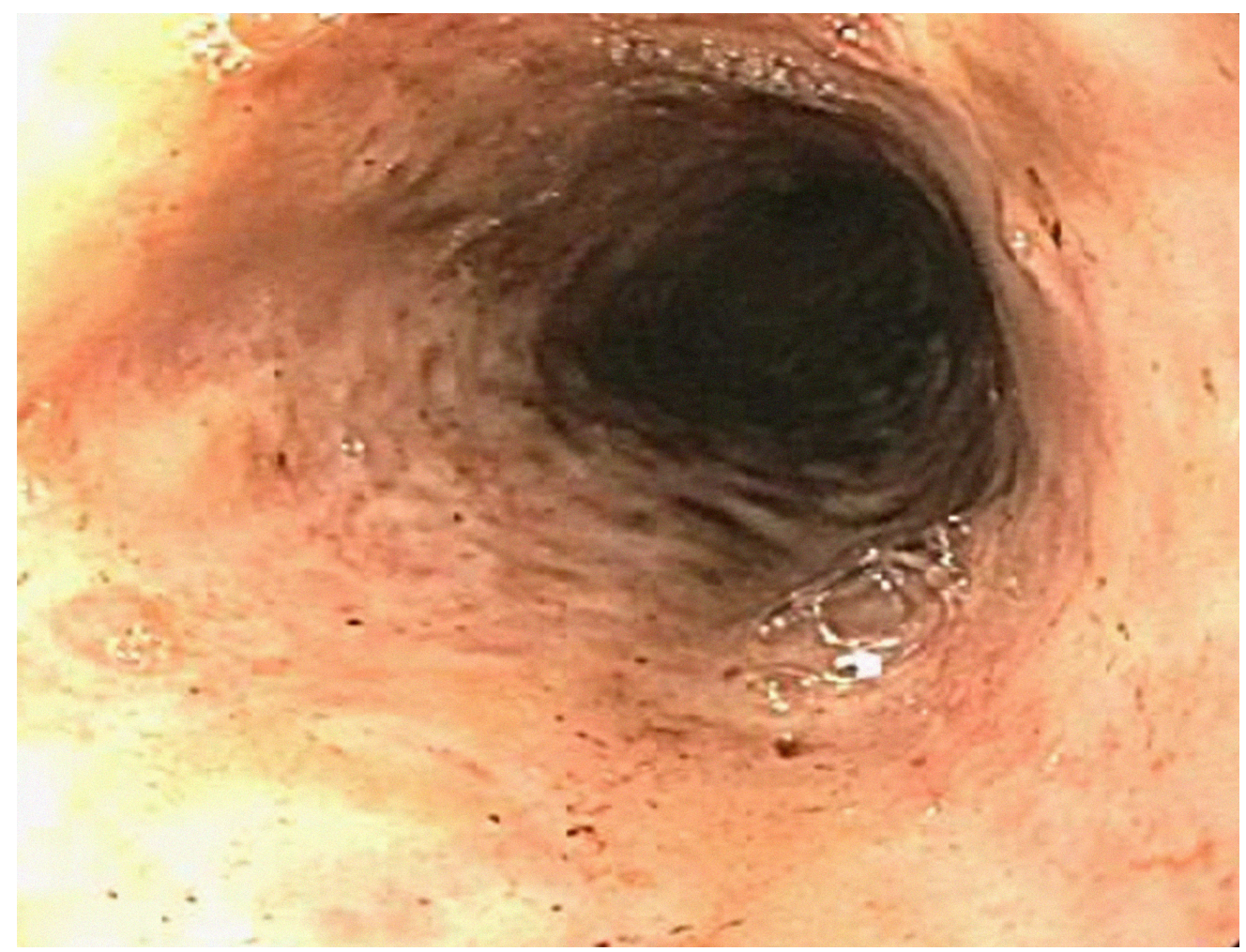

Figure 1. Endoscopic image of the patient's upper esophagus demonstrating relatively normal mucosa.

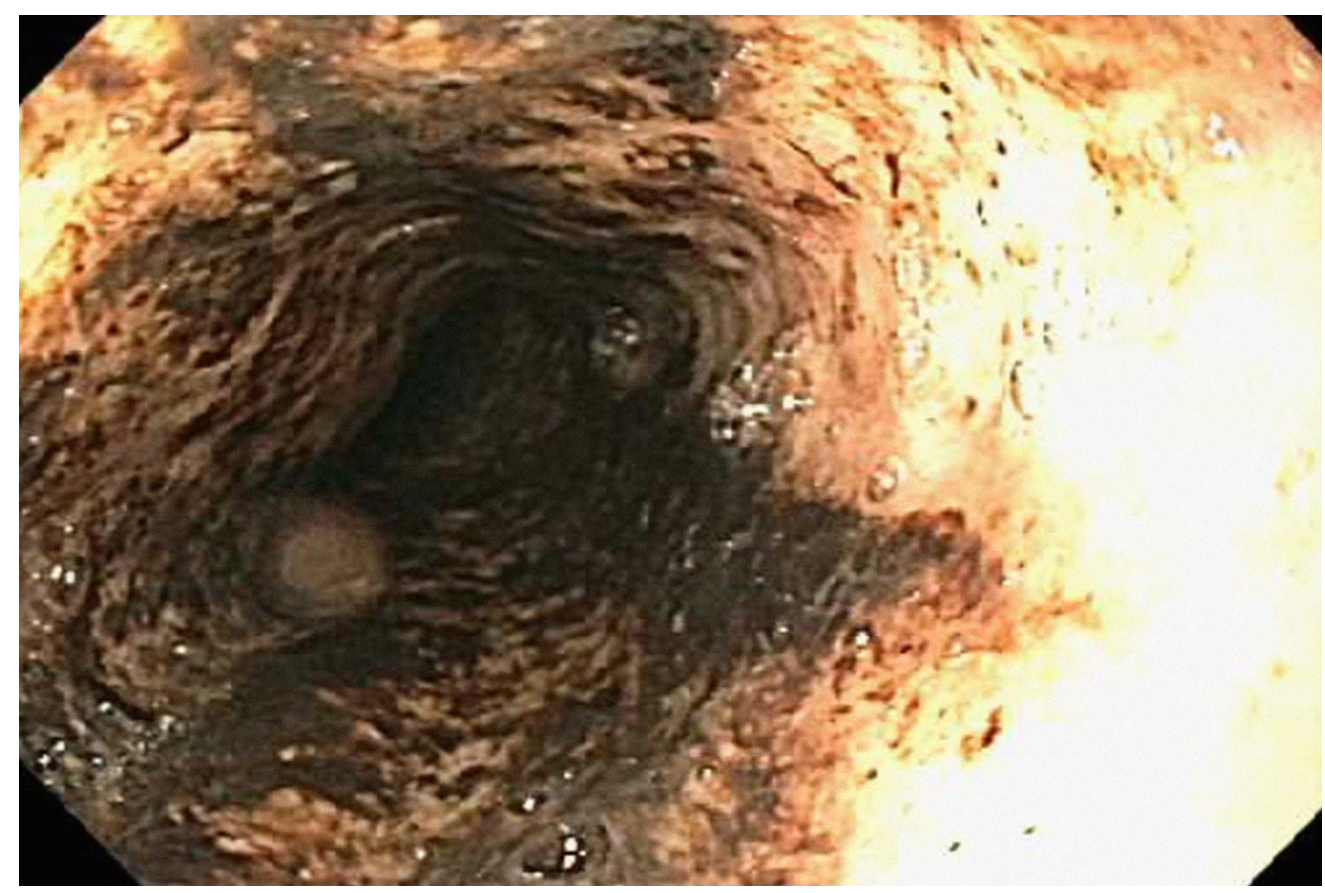

Figure 2. Endoscopic image of the distal third of the patient's esophagus demonstrating circumferential necrosis. 


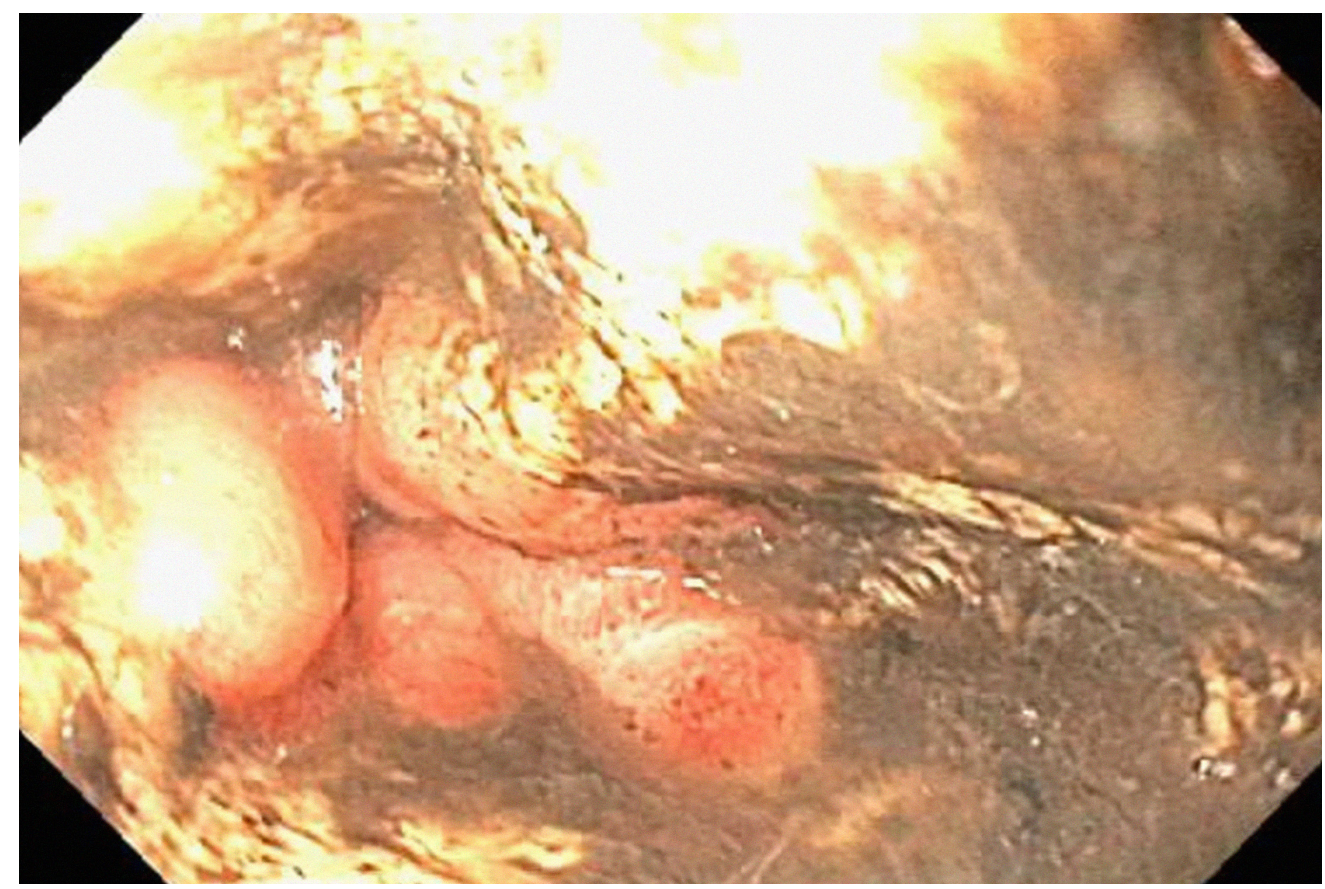

Figure 3. Endoscopic image of the distal third of the patient's esophagus demonstrating circumferential necrosis that abruptly stops at the gastroesophageal junction.

Patients with black esophagus typically present for evaluation as a result of GI bleeding, which occurs in $65 \%$ to $90 \%$ of cases. ${ }^{9,10}$ This condition is more common in elderly patients with a disproportionately higher incidence in men, who represent approximately $80 \%$ of cases. A variety of comorbidities are associated with AEN, most commonly diabetes mellitus, malignancy, hypertension, renal insufficiency, heart disease, and duodenal ulcer. ${ }^{5,10}$ In a recent case series by Gurvits et al, ${ }^{11}$ tachycardia or hypotension was observed in $90 \%$ of cases.

\section{Diagnosis}

Black esophagus is defined by diffuse, circumferential necrosis of the esophagus with preferential involvement of the distal third of the esophagus that abruptly stops at the gastroesophageal junction, and in the absence of caustic ingestion..$^{12}$ The predilection toward involvement of the distal esophagus is thought to be due to its relatively poor perfusion. Blood flow to the distal esophagus is highly variable, but typically occurs through the left gastric and left inferior phrenic arteries. This is believed to result in a "watershed region" that creates a susceptibility to insult., ${ }^{7,13}$ Histologically, there is necrosis of the mucosa and submucosa, inflammation of the muscle fibers, and occasional thrombosis of blood vessels. ${ }^{4}$ However, gross findings alone are sufficient for diagnosis, and biopsy is not mandatory. ${ }^{1,14}$

\section{Etiology}

The etiology of acute esophageal necrosis is not well understood. The prevailing theory is that the combination of an ischemic insult and reflux of gastric contents leads to mucosal destruction. The watershed distribution of blood flow to the distal esophagus is thought to predispose patients to ischemia or thrombosis. ${ }^{5,7,10}$ As previously mentioned, 
a recent series by Gurvits et al ${ }^{11}$ demonstrated that $90 \%$ of patients with black esophagus also develop tachycardia or hypotension. Further, many of the comorbid conditions noted in cases of AEN are characterized by a tendency toward malperfusion or thrombosis.

\section{Management}

The mainstay of managing black esophagus in the ED is aggressive fluid resuscitation, bowel rest, and treatment with IV PPIs. Antibiotics are not indicated unless the patient has an infection, is immunocompromised, continues to decompensate despite adequate IV fluid resuscitation, or has an esophageal perforation. ${ }^{7,11}$ In practice, the necessity of early antibiotic therapy may be unclear in the ED due to other considerations in the differential diagnosis; therefore, it is prudent to treat the patient empirically until these etiologies can be ruled out. Some clinicians recommend sucralfate due to its ability to bind pepsin and stimulate mucus secretion which theoretically prevents further esophageal injury. ${ }^{4}$ The initiation of sucralfate should be deferred until after endoscopy.

Esophageal strictures are the most common complication of black esophagus, developing in $16 \%$ to $25 \%$ of cases. Due to underlying disease, AEN is associated with a highmortality of $12.5 \%$ to $36 \%{ }^{4,11}$ Mortality as a direct result of esophageal necrosis is less than $6 \% .{ }^{10}$ Complications of black esophagus include perforation and mediastinitis, both of which are indications for emergent surgical intervention. ${ }^{1,15}$

Emergency physicians traditionally manage GI bleeding with conservative measures and early involvement of gastroenterology services. Failure of patients to respond to traditional resuscitative measures may signal mediastinitis and require immediate surgical intervention. This infrequent diagnosis represents a significant deviation from the typical presentations seen by EPs in standard practice; for this reason, EPs should be aware of the signs and symptoms associated with black esophagus and consider it in the differential diagnosis of patients presenting with GI bleeding.

\section{Summary}

Emergency physicians are often the first providers to care for patients with an upper GI hemorrhage. While the mainstay of treatment of hematemesis is resuscitation with intravenous fluids and blood products, EPs must be aware of the potential etiologies that may change management. Black esophagus is a rare but important cause of hematemesis-a condition that can lead to esophageal perforation and mediastinitis. In cases wherein patients fail to respond to appropriate resuscitation, subsequently decompensate despite resuscitation, or appear septic, EPs should consider IV broad-spectrum antibiotics and surgical consultation.

\section{References}

1. Shafa S, Sharma N, Keshishian J, Dellon ES. The black esophagus: a rare but deadly disease. ACG Case Rep J. 2016;3(2):88-91. doi:10.14309/crj.2016.9.

2. Brennan JL. Case of extensive necrosis of the oesophageal mucosa following hypothermia. J Clin Pathol. 1967;20(4):581-584.

3. Goldenberg SP, Wain SL, Marignani P. Acute necrotizing esophagitis. Gastroenterology. 1990;98(2):493-496.

4. Lacy BE, Toor A, Bensen SP, Rothstein RI, Maheshwari Y. Acute esophageal necrosis: report of two cases and a review of the literature. Gastrointest Endosc. 1999;49(4 Pt 1):527-532.

5. Grudell ABM, Mueller PS, Viggiano TR. Black esophagus: report of six cases and review of the literature, 19632003. Dis Esophagus. 2006;19(2):105-110. doi:10.1111/j.1442-2050.2006.00549.x.

6. Moretó M, Ojembarrena E, Zaballa M, Tánago JG, Ibánez S. Idiopathic acute esophageal necrosis: not necessarily a terminal event. Endoscopy. 1993;25(8):534-538.

7. Gurvits GE. Black esophagus: acute esophageal necrosis syndrome. World J Gastroenterol. 2010;16(26):3219-3225.

8. Yasuda H, Yamada M, Endo Y, Inoue K, Yoshiba M. Acute necrotizing esophagitis: role of nonsteroidal anti-inflammatory drugs. J Gastroenterol. 2006;41(3):193-197. doi:10.1007/s00535-005-1741-6.

9. Zacharia GS, Sandesh K, Ramachandran T. Acute esophageal necrosis: an uncommon cause of hematemesis. Oman Med J. 2014;29(4):302-304. doi:10.5001/omj.2014.79. 
10. Gurvits GE, Shapsis A, Lau N, Gualtieri N, Robilotti JG. Acute esophageal necrosis: a rare syndrome. J Gastroenterol. 2007;42(1):29-38. doi:10.1007/s00535-006-1974-z.

11. Gurvits GE, Cherian K, Shami MN, et al. Black esophagus: new insights and multicenter international experience in 2014. Dig Dis Sci. 2015;60(2):444-453. doi:10.1007/s10620-014-3382-1.

12. Burtally A, Gregoire P. Acute esophageal necrosis and low-flow state. Can J Gastroenterol. 2007;21(4):245-247.

13. Bear BC, Mathew J, Parker CW III. Acute esophageal necrosis: black esophagus in setting of diabetic ketoacidosis. J Case Rep Images Med. 2015;1:18-21.

14. Altenburger DL, Wagner AS, Li S, Garavaglia J. A case of black esophagus with histopathologic description and characterization. Arch Pathol Lab Med. 2011;135(6):797-798. doi:10.1043/2010-0128-C.1.

15. Hwang J, Weigel TL. Acute esophageal necrosis: "black esophagus.” JSLS. 2007;11(1):165-167. 